\title{
P. Chamoiseau, La matière de l'absence
}

\section{Roberto Ferraroni}

\section{(2) OpenEdition}

\section{Journals}

\section{Edizione digitale}

URL: http://journals.openedition.org/studifrancesi/10624

DOI: 10.4000/studifrancesi. 10624

ISSN: 2427-5856

\section{Editore}

Rosenberg \& Sellier

\section{Edizione cartacea}

Data di pubblicazione: 1 décembre 2017

Paginazione: 596

ISSN: 0039-2944

\section{Notizia bibliografica digitale}

Roberto Ferraroni, «P. Chamoiseau, La matière de l'absence», Studi Francesi [Online], 183 (LXI | III) | 2017, online dal 01 février 2018, consultato il 22 janvier 2021. URL: http://journals.openedition.org/ studifrancesi/10624 ; DOI: https://doi.org/10.4000/studifrancesi.10624

Questo documento è stato generato automaticamente il 22 janvier 2021.

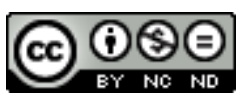

Studi Francesi è distribuita con Licenza Creative Commons Attribuzione - Non commerciale - Non opere derivate 4.0 Internazionale. 


\title{
P. Chamoiseau, La matière de l'absence
}

\author{
Roberto Ferraroni
}

\section{NOTIZIA}

PATRICK CHAMOISEAU, La matière de l'absence, Paris, Seuil, 2016, 365 pp.

2016

1 Patrick Chamoiseau, autore martinicano che ha fatto della sua arte di scrivere il mezzo per trasmettere le proprie radici al grande pubblico di lettori che lo segue, ci offre, con il suo romanzo, un viaggio alla scoperta delle origini della cultura, delle tradizioni, della storia dei Caraibi. Questo è ciò che si potrebbe pensare analizzando la sola superficie del romanzo che, al contrario, è molto di più. Le tradizioni martinicane fanno, in effetti, da contorno a un'opera che è fortemente intimistica e che si distacca in parte dalla tradizione letteraria delle Antille, spesso volta a far parlare il "noi", le persone come membri di una comunità, unite da radici condivise. Chamoiseau ci presenta chiaramente anche questo aspetto, ma lo fa partendo da un'esperienza personale, intima, profonda che rende l'“io" dell'autore il vero protagonista del romanzo.

2 Il punto di partenza dell'opera è la morte della madre dello scrittore, evento che ha portato un grande cambiamento nella sua vita, che ha praticato un taglio netto con il passato, che ha operato come uno spartiacque tra ciò che era "prima" e ciò che è stato "dopo". Un trauma che ha suscitato nell'autore un senso di vuoto, di incompletezza, una mancanza, quell'assenza appunto che ci viene presentata subito nel titolo. Tuttavia, nonostante la collocazione in posizione volutamente forte, l'absence ricompare soltanto in altre due occasioni nel corso della narrazione: nella prima frase quando la Baronne, sorella maggiore così soprannominata dai fratelli più piccoli, afferma che «ceux qui vivent longtemps se nourrissent de l'absence» (p. 15); e poi a poche righe dalla fine quando l'autore afferma che «l'auto-initiation... serait une transmutation de la matière improbable de l'absence» (p. 363). Una scelta particolare, 
che può essere legata al valore che Chamoiseau dà all'assenza, perché quella che lui ci presenta non sembra essere un'assenza vuota, bensì un'assenza piena; dal vuoto lasciato dalla morte della madre nascono pensieri, ricordi, sensazioni. È come se un evento così traumatico risvegliasse ciò che in lui è rimasto sopito fino a quel momento, permettendogli di viaggiare nel passato e riportando alla luce parti di sé ormai dimenticate. Questa assenza piena libera la creatività, permettendo all'autore di creare un legame tra lui e i suoi antenati, quegli antenati che avevano dovuto sopportare perdite altrettanto violente durante la tratta degli schiavi neri, nelle stive delle navi, e che avevano trovato la forza per reagire e sopravvivere. La dipartita della madre che divide la vita tra "prima" e "dopo" dà il via a un'auto-iniziazione che l'autore, e in generale qualsiasi uomo, deve affrontare da solo, con le proprie forze. Solo così sarà in grado di affrontare la vita del "dopo".

3 Il romanzo è diviso in tre parti intitolate impact, éjectats e cratère. Il riferimento all'astronomia è abbastanza chiaro, soprattutto se si considera il fascino che l'oscurità, fisica e metaforica, dell'universo ha sempre esercitato su Chamoiseau. L'impatto di un meteorite su un corpo celeste ha la stessa violenza che la morte della madre ha avuto sull'autore; quando parla di «éjectats» si riferisce ai segni, alle voragini, ai solchi più o meno profondi provocati dall'impatto, che sono apparsi sulla superficie del corpo celeste, così come i ricordi dell'autore ritornano alla luce quando rientra in contatto con gli oggetti e le foto che la madre ha lasciato dopo la sua morte e di cui Chamoiseau ci parla nella seconda parte del romanzo. E infine il cratere, ciò che è effettivamente rimasto del pianeta dopo lo scontro con il meteorite, ciò che rimane di se stesso dopo il trauma della morte materna, un corpo modificato, metaforicamente mutilato, ma pur sempre vivo.

4 La morte della madre, Man Ninotte, è sopraggiunta il 31 dicembre 1999 ed è stato un evento che ha segnato - e segna - in maniera indelebile la vita di Chamoiseau, pur essendo egli consapevole che la morte è parte della vita. Nel romanzo si trasforma nel punto di partenza per una riflessione poetica sulla Martinica, sulle origini dell'uomo, sull'evoluzione dell'uomo contemporaneo.

5 L'intero romanzo è permeato dall'intellettualismo dell'autore, che però viene più volte smorzato dal suo umorismo, quando decide di intervallare le sue digressioni impegnate con ricordi di scambi di opinione con la Baronne, che costantemente sembra deridere bonariamente la seriosità del fratello minore. Grazie a questi momenti di leggerezza, l'intento didascalico dell'autore viene mitigato, trasformando l'opera in un piacevole viaggio alla scoperta delle verità più nascoste dell'uomo martinicano e, in senso lato, del genere umano nel suo insieme. 